\title{
Cinética Ruminal das Frações de Carboidratos, Produção de Gás, Digestibilidade In Vitro da Matéria Seca e NDT Estimado da Silagem de Milho com Diferentes Proporções de Grãos ${ }^{1}$
}

\author{
Luciano da Silva Cabral ${ }^{2}$, Sebastião de Campos Valadares Filho ${ }^{3}$, Edenio Detmann ${ }^{4}$, Joanis \\ Tilemahos Zervoudakis, Odilon Gomes Pereira ${ }^{3}$, Rafael Gonçalves Veloso ${ }^{5}$, Elzânia Sales Pereira ${ }^{6}$
}

\begin{abstract}
RESUMO - Foram objetivos do presente trabalho avaliar as alterações na composição bromatológica e nas frações nitrogenadas e de carboidratos, estimar a taxa de digestão dos carboidratos fibrosos (CF) e não-fibrosos (CNF), determinar a digestibilidade in vitro da matéria seca (DIVMS) e estimar o teor de nutrientes digestíveis totais (NDT) da silagem de milho com diferentes proporções de grãos. As silagens foram confeccionadas nas seguintes proporções de grãos: 0, 15, 30, 45 e 60\%. Foram determinados os teores de matéria seca (MS), compostos nitrogenados $(\mathrm{N})$, extrato etéreo (EE), matéria mineral (MM), fibra em detergente neutro (FDN) e fibra em detergente ácido (FDA), bem como os compostos nitrogenados não-protéicos (NNP) e as frações nitrogenadas $\mathrm{B}_{1}+\mathrm{B}_{2}$, $\mathrm{B}_{3}$ e $\mathrm{C}$. Foram também determinados os teores dos carboidratos não-fibrosos (CNF) e das frações potencialmente digestíveis ( $\mathrm{B}_{2}$ ) e indigestíveis da FDN (C). As taxas de digestão dos $\mathrm{CNF}$ e da fração $\mathrm{B}_{2}$ dos carboidratos totais foram estimadas por meio da técnica de produção de gases. Foram, ainda, realizadas a DIVMS por meio da técnica de dois estádios e a estimação do NDT por intermédio da composição química. $\mathrm{O}$ acréscimo de grãos à silagem aumentou linearmente os teores de MS, N e CNF e reduziu a MM, FDN, FDA e lignina. O NNP e as frações B e $^{\mathrm{C}}$ variaram de 34,04 a 54,62\%, 6,63 a 2,61 e 7,83 a 1,32\% da PB. Os teores dos CNF e das frações $\mathrm{B}_{2}$ e $\mathrm{C}$ dos carboidratos totais foram influenciados linearmente pela adição de grãos à silagem, que variaram de 153,55 a 585,10; 489,57 a 203,29; e 233,50 a 85,51 g/kg de MS, respectivamente. As taxas de digestão dos CNF e da fração $\mathrm{B}_{2}$ apresentaram comportamento quadrático, sendo os valores máximos estimados de 0,2723 e $0,02771 \mathrm{~h}^{-1}$, para as silagens com 40,08 e 14,57\% de grãos, respectivamente. O volume final de gás, a DIVMS e o NDT estimado, aumentaram linearmente, em função da porcentagem de grãos, os quais variaram de 20,03 a 28,47 mL, 62,19 a 83,21 e 56,08 a 81,40\%, respectivamente.
\end{abstract}

Palavras-chave: cinética, digestão, milho, silagem

\section{Ruminal Kinetic of Carbohydrate Fractions, Gas Production, Dry Matter In Vitro Digestibility and Estimated TDN of Corn Silage with Different Grain Proportions}

ABSTRACT - The objectives of this work were to evaluate the chemical composition alteration, the nitrogen and carbohydrate fractions changes, to estimate the digestion rate of non-fiber carbohydrate (NFC) and fiber carbohydrate (FC), to determine the in vitro dry matter digestibility (IVDMD) and to estimate the TDN of corn silage with different grain proportions. The silage were done in the following proportions: $0,15,30,45$ e $60 \%$ of grain. The amount of dry matter (DM), nitrogen compounds (N), ether extract (EE), ash, neutral detergent fiber (NDF) and acid detergent fiber (ADF), as well the non-protein nitrogen compounds $(\mathrm{NPN})$ and the $\mathrm{B}_{1}+\mathrm{B}_{2}, \mathrm{~B}_{3}$ and $C$ nitrogen fractions, were determined. The amount of non-fiber carbohydrate (NFC) and of potentially digestible $\left(\mathrm{B}_{2}\right)$ and indigestible (C) fractions of NDF were also determined. The rate digestion of NFC and $\mathrm{B}_{2}$ fraction of carbohydrate were estimated by mean of gas production technique. IVDMD was determined by the two-stage technique and the TDN content was estimated by the chemical composition. The addition of grain to the corn silage showed linear increase in DM, N and NFC contents and reduced the ash, NDF, $\mathrm{ADF}$ and lignin. The NPN and $\mathrm{B}_{3}$ and $\mathrm{C}$ fractions ranged from 34.04 to 54.62 , from 6.63 to 2.61 and from 7.83 to $1.32 \%$ of the total $\mathrm{N}$. The amount of the NFC and $\mathrm{B}_{2}$ and $\mathrm{C}$ fractions of carbohydrate were linearly influenced by grain addition in the corn silage, that ranged from 135.55 to $558.10,489.57$ to 203.29 and from 233.50 to $85.51 \mathrm{~g} / \mathrm{kg}$ of DM. The digestion rate of the NFC and $\mathrm{B}_{2}$ fraction were quadraticly affected, and the maximum estimated values were of 0.2723 and $0.02771 \mathrm{~h}^{-1}$, for the silage with 40.08 and $14.57 \%$ of grains, respectively. The total gas production, IVDMD and TDN increased linearly as a function of grain percentage, that ranged from 20.03 to 28.47 , from 62.19 to 83.21 and from 56.08 to 81.40 , respectively.

Key Words: corn silage, digestion, kinetic

\footnotetext{
1 Parte da tese apresentada à UFV para obtenção do título Doctor Scientiae.

2 Professor Adjunto da UFMT, Cuiabá - MT. E.mail: cabralls@terra.com.br

${ }^{3}$ Professor da UFV, Viçosa - MG.

${ }^{4}$ Professor da UFMS.

5 Estudante de Doutorado - UFV.

${ }^{6}$ Estudante de Mestrado - UFV.

${ }^{7}$ Professor da UNIOESTE, Mal. Cândido Rondon, PR.
} 


\section{Introdução}

Os carboidratos, nos vegetais, derivam da fixação do $\mathrm{CO}_{2}$ atmosférico, no processo conhecido como ciclo de Calvin, exercido pelos seres fotoautotróficos, onde a energia luminosa é convertida em energia química durante a fotossíntese nas membranas tilacóides dos cloroplastos (Brock et al., 1994). São nesses seres vivos que se verifica a classe de compostos mais abundantes da biosfera, seja na forma de mono e dissacarídeos (glicose e sacarose), através dos quais a energia é translocada nas diversas partes da planta, como polímeros de reserva amido, frutosanas e, principalmente, na forma de polissacarídeos da parede celular (celulose, hemicelulose) -, desempenhando funções de proteção e sustentação.

Para os herbívoros, os carboidratos são a principal fonte de energia, tanto diretamente, através da absorção de seus monômeros constituintes pelo trato digestivo, como, indiretamente, pela sua conversão em ácidos graxos voláteis através da ação fermentativa de microrganismos. Suportam, ainda, a síntese de proteína microbiana nos compartimentos fermentativos dos ruminantes, a qual é a principal fonte de aminoácidos disponíveis nos intestinos desses animais (Van Soest, 1994).

Do ponto de vista nutricional, os carboidratos podem ser classificados em carboidratos não-fibrosos (CNF), ou conteúdo celular mais a pectina, e carboidratos fibrosos (CF) (Mertens, 1996). Os primeiros apresentam disponibilidade nutricional rápida, completa e constante entre os alimentos (98 a 100\%), já os CF (celulose e hemicelulose), os quais juntamente com a lignina compõem a parede celular vegetal, são lentamente digeridos, apresentam disponibilidade nutricional variável e ocupam espaço no trato gastrintestinal (Van Soest, 1967).

Nos trópicos, a existência de duas estações distintas, águas e seca, determina a abundância na produção de matéria seca em uma época e escassez extrema em outra. Conseqüentemente, o desempenho dos rebanhos fica limitado, pela falta de oferta de alimentação na época seca do ano. Dessa forma, o armazenamento do excesso de forragem proveniente da época das águas para o período da seca constitui-se em estratégia de grande impacto na viabilidade da atividade. Nesse contexto, a ensilagem é ferramenta fundamental na conservação de alimentos, principalmente no Brasil, onde a fenação é limitada por variáveis climáticas predominantes em grande parte do país. Entretanto, o valor nutricional do produto final é função, além das técnicas de ensilagem, da qualidade do material ensilado, que, no caso da silagem de milho, varia, principalmente com a proporção de grãos. Normalmente, a adequação de dietas é feita considerando-se a composição química dos alimentos oriunda de valores médios de tabelas. No caso da silagem de milho, esta estratégia pode conduzir a sérios equívocos, uma vez que a porcentagem de grãos não é constante.

Dessa forma, foi objetivo do presente trabalho avaliar as alterações na silagem de milho, em função de seu teor de grãos.

\section{Material e Métodos}

O milho (Zea mays), híbrido AG 1051, utilizado neste estudo foi cultivado em área do Departamento de Zootecnia da UFV-MG, cujo plantio foi realizado em outubro de 1998, de acordo com as recomendações do frabricante de sementes. Como adubação de plantio, foram aplicados $300 \mathrm{~kg} / \mathrm{ha}$ de 8-28-16 (N-P$\mathrm{K})$ e, como adubação de cobertura aos 25 e 45 dias de plantio, $150 \mathrm{~kg} / \mathrm{ha}$ da mistura 20-0-20 e $100 \mathrm{~kg} / \mathrm{ha}$ de uréia, respectivamente. A colheita foi realizada de forma manual, por meio de um facão, a aproximadamente $10 \mathrm{~cm}$ do solo, quando os grãos atingiram o estádio farináceo-duro (110 dias), sendo as plantas, em seguida, conduzidas ao laboratório de animais dos DZO. Trinta plantas foram tomadas aleatoriamente e separadas em duas partes: colmo+folha e espigas, para determinação da proporção de cada parte na planta inteira. Em seguida, cada parte (colmo+folha e espigas) foi picada separadamente e ensilada em silos laboratoriais de PVC de 40 x $10 \mathrm{~cm}$, dotados de válvula de Bunsen, nas proporções de 0, 25, 50, 75 e $100 \%$ de espigas, com três repetições em um delineamento inteiramente casualizado. Para determinação do teor de grãos nas espigas e na planta inteira, 30 espigas foram tomadas aleatoriamente e separadas em palha, sabugo e grãos, sendo cada parte pesada e seca a $55^{\circ} \mathrm{C}$. Assim, os tratamentos foram constituídos de $0,15,30,45$ e $60 \%$ de grãos. Os silos foram abertos um mês após a ensilagem e, nas amostras frescas, determinado o nitrogênio não-protéico(NNP), conforme Broderick (comunicação pessoal). O restante do material foi pré-seco a $55^{\circ} \mathrm{C}$ durante 72 horas e moído em peneira de $1 \mathrm{~mm}$, para posterior análise de matéria seca (MS), proteína bruta (PB),

R. Bras. Zootec., v.31, n.6, p.2332-2339, 2002 
matéria mineral (MM) e extrato etéreo (EE), conforme AOAC (1990). As análises de fibra insolúvel nos detergentes neutro (FDN) e ácido (FDA) foram feitas em autoclave, conforme Pell \& Schofield (1993), e lignina, conforme Van Soest et al. (1991). Os compostos nitrogenados insolúveis nos detergentes neutro (NIDN) e ácido (NIDA) foram determinados conforme Licitra et al. (1996).

Os carboidratos totais (CT) foram determinados conforme Sniffen et al. (1992), sendo as suas frações: carboidratos fibrosos (CF), considerados como a FDN corrigida para o seu conteúdo em cinzas e proteínas (FDNcp); carboidratos não-fibrosos (CNF), obtido pela subtração da FDNcp dos CT; e a fração C, obtida pela FDN indigerível após 144 horas de incubação in situ (Sniffen et al., 1992). A fração $B_{2}$, ou seja, fração disponível da fibra, foi obtida pela diferença entre a FDNcp e a fração C.

As taxas de digestão dos CNF e da fração $\mathrm{B}_{2}$ dos CT foram estimadas pela técnica de produção de gases, conforme Pell \& Schofield (1993), com algumas adaptações. As incubações foram realizadas em frascos de vidro com capacidade de $50 \mathrm{~mL}$, onde foram pesados aproximadamente $100 \mathrm{mg}$ de substrato. Aos frascos foram adicionados $8 \mathrm{~mL}$ de tampão de McDougal (McDougal, 1949), previamente reduzido com $\mathrm{CO}_{2}$ (pH 6,9-7,0), e 2 mL de inóculo, proveniente de um bovino fistulado no rúmen, filtrado em camada dupla de gaze sob aspersão de $\mathrm{CO}_{2}$. Imediatamente após, os frascos receberam tampa de borracha e lacre de alumínio. As leituras de pressão foram realizadas por meio de um sensor de pressão acoplado a um voltímetro, nos seguintes tempos: 1 , $2,3,4,5,6,9,12,18,24,30,36,48,60$ e 72 horas. As leituras realizadas em volts foram convertidas para mL de gás, conforme Pell e Schofield (1993). A cinética da produção cumulativa dos gases foi analisada empregando-se o modelo logístico bicompartimental (Schofield et al., 1994):

$\mathrm{V}(\mathrm{t})=\mathrm{Vf}_{1} /\left(1+\exp \left(2-4 * c_{1} *(\mathrm{~T}-\mathrm{L})\right)\right)+\mathrm{Vf}_{2} /\left(1+\mathrm{EXP}\left(2-4 * c_{2} *(\mathrm{~T}-\mathrm{L})\right)\right)$

no qual V(t) é o volume acumulado no tempo $\mathrm{t}$; $\mathrm{Vf}_{1}$, o volume de gás oriundo da fração de rápida digestão $(\mathrm{CNF}) ; c_{1}\left(\mathrm{~h}^{-1}\right)$, a taxa de degradação da fração de rápida digestão (CNF); $\mathrm{L}$, a latência; e T, o tempo (h); $\mathrm{Vf}^{2}$, o volume de gás da fração de lenta degradação $\left(\mathrm{B}_{2}\right) ; c_{2}\left(\mathrm{~h}^{-1}\right)$, a taxa de degradação da fração $\mathrm{B}_{2}$. Para realização dos ajustes, utilizou-se o processo iterativo do algoritmo de Marquadt, implanta- do no software Sistema de Análises Estatísticas e Genéticas - SAEG (UFV, 1993).

A digestibilidade in vitro da matéria seca (DIVMS) foi determinada pelo método de dois estádios, conforme Tilley \& Terry (1963), e o NDT estimado, conforme NRC (2001), a partir das seguintes equações:

$\mathrm{NDT}=\mathrm{CNFD}+\mathrm{PBD}+\mathrm{FDND}+\mathrm{AGD} * 2,25-7$

em que $\mathrm{CNFD}=\mathrm{CNF}^{*} 0,98$;

$\mathrm{PBD}=\mathrm{PB} * \mathrm{EXP}(-1,2 *(\mathrm{PIDA} / \mathrm{PB}))$;

$\mathrm{FDND}=0,75^{*}(\mathrm{FDNn}-\mathrm{L}) *(1-(\mathrm{L} / \mathrm{FDNn}) 0,667)$

$\mathrm{AGD}=\mathrm{EE}-1$ e 7, refere-se ao NDT metabólico fecal, em que CNFD representa os carboidratos não-fibrosos verdadeiramente digeríveis; $\mathrm{PBD}$, a PB verdadeiramente digerível; GD, os ácidos graxos verdadeiramente digeríveis; FDND, a FDN digerível; LIG, a lignina; e -7, o NDT metabólico fecal.

As análises estatísticas foram conduzidas segundo um delineamento inteiramente casualizado, segundo o modelo:

$$
\mathrm{Y}_{\mathrm{ij}}=\mu+\mathrm{T}_{\mathrm{i}}+\mathrm{E}_{(\mathrm{i}) \mathrm{j}}
$$

em que $\mu=$ constante geral; $T_{i}=$ efeito relativo ao tratamento ou teor de espigas i, sendo $i=1,2,3,4$ e 5 ; $\mathrm{E}_{(\mathrm{i}) \mathrm{j}}=$ erro aleatório associado a cada observação, pressuposto NID $\left(0, \sigma^{2}\right)$.

As comparações entre médias foram realizadas por intermédio de análise de regressão linear, adotando-se $\alpha=0,05$. A escolha do modelo ocorreu com base nos testes de significância para os coeficientes de regressão, no coeficiente de determinação $\left(\mathrm{r}^{2} / \mathrm{R}^{2}\right)$ e na ocorrência de falta de ajustamento. Os coeficientes de determinação foram expressos como a razão entre a soma de quadrados da regressão e a soma de quadrados total.

\section{Resultados e Discussão}

De acordo com o aspecto visual, o odor, o pH das silagens e o fato de que não foi verificada putrefação em qualquer silagem, pode-se inferir que houve fermentação adequada das silagens.

A composição bromatológica da silagem de milho com proporções crescentes de grãos é apresentada na Tabela 1 , considerando que a porcentagem média de grãos nas espigas foi de $60 \%$. O acréscimo de grãos à silagem de milho acarretou aumento linear da MST $(\mathrm{P}<0,01), \mathrm{PB}(\mathrm{P}<0,01)$ e dos CNF e redução da $\mathrm{MM}(\mathrm{P}<0,01)$, FDN $(\mathrm{P}<0,01)$, FDA $(0,01)$ e lignina $(\mathrm{P}<0,01)$. A porcentagem de FDN e EE, bem como o NDT estimado para silagem com $45 \%$ de grãos, está

R. Bras. Zootec., v.31, n.6, p.2332-2339, 2002 
Tabela 1 - Teores médios e equações de regressão para a matéria seca (MS), proteína bruta (PB), matéria mineral (MM), extrato etéreo (EE), carboidratos totais (CT), fibra insolúvel em detergente neutro (FDN), carboidratos nãofibrosos (CNF), fibra insolúvel em detergente ácido (FDA) e lignina, em função das porcentagens de grãos (Grão) da silagem de milho e os respectivos coeficientes de determinação $\left(\mathrm{r}^{2}\right)$

Table 1 - Average contents and regression equations of dry matter (DM), crude protein (CP), ash, ether extract (EE), total carbohydrates (TC), neutral detergent fiber (NDF), non-fiber carbohydrates (NFC), acid detergent fiber (ADF) and lignin, in function of grains percentage (Grão) of corn silage and the respective coefficients of determination $\left(r^{2}\right)$

\begin{tabular}{|c|c|c|c|c|c|c|c|}
\hline \multirow[t]{2}{*}{ Item } & \multicolumn{5}{|c|}{$\begin{array}{l}\text { Grãos (\%) } \\
\text { Grains (\%) }\end{array}$} & \multirow[t]{2}{*}{$\begin{array}{l}\text { Equação de regressão } \\
\text { Regression equation }\end{array}$} & \multirow[t]{2}{*}{$\mathrm{r}^{2}$} \\
\hline & 0 & 15 & 30 & 45 & 60 & & \\
\hline $\begin{array}{l}\text { MS (\%) } \\
D M(\%)\end{array}$ & 19,36 & 24,48 & 27,84 & 30,96 & 38,48 & $\hat{Y}=19,12+0,3012 *$ Grão & 0,9550 \\
\hline $\begin{array}{l}\mathrm{PB}^{1} \\
C P\end{array}$ & 4,89 & 5,95 & 6,47 & 7,06 & 7,72 & $\hat{Y}=5,07+0,045 *$ Grão & 0,9026 \\
\hline $\begin{array}{l}\mathrm{MM}^{1} \\
\text { Ash }\end{array}$ & 5,20 & 4,82 & 3,46 & 2,32 & 1,70 & $\hat{Y}=5,38-0,0379 *$ Grão & 0,9531 \\
\hline $\begin{array}{l}\mathrm{EE}^{1} \\
\text { Ether extract }\end{array}$ & 2,25 & 2,58 & 2,66 & 2,92 & 3,89 & - & - \\
\hline $\begin{array}{l}\mathrm{CT}^{1} \\
\mathrm{TC}\end{array}$ & 87,68 & 86,57 & 87,47 & 87,67 & 86,69 & - & - \\
\hline $\begin{array}{l}\mathrm{FDN}^{1} \\
N D F\end{array}$ & 73,46 & 57,45 & 51,79 & 40,63 & 29,36 & $\hat{Y}=71,54-0,7001 *$ Grão & 0,9728 \\
\hline $\begin{array}{l}\mathrm{CNF}^{1} \\
\mathrm{NFC}\end{array}$ & 15,35 & 30,27 & 37,03 & 48,13 & 58,37 & $\hat{Y}=17,05+0,6927 *$ Grão & 0,9795 \\
\hline $\begin{array}{l}\mathrm{FDA}^{1} \\
A D F\end{array}$ & 42,56 & 32,56 & 25,94 & 21,08 & 17,08 & $\hat{Y}=40,19-0,414 *$ Grão & 0,9458 \\
\hline $\begin{array}{l}\text { Lignina }^{2} \\
\text { Lignin }\end{array}$ & 8,13 & 8,15 & 6,12 & 4,85 & 2,54 & $\hat{Y}=8,74-0,093 *$ Grão & 0,8475 \\
\hline
\end{tabular}

$1 \%$ na MS (\% DM).

$2 \%$ na FDN (\% NDF).

Tabela 2 - Valores médios e equação de regressão para os compostos nitrogenados não-protéicos (NNP), frações $B_{1}+B_{2}, B_{3}$ e $C$ e nitrogênio insolúvel em detergente neutro (NIDN) na silagem de milho com diferentes porcentagens de grãos (Grão) e os respectivos coeficientes de determinação $\left(r^{2}\right)$

Table 2 - Average values and regression equation for the non-protein nitrogen (NPN), $B_{1}+B_{2}, B_{3}$ and $C$ fractions and neutral detergent insoluble nitrogen (NDIN) in corn silage with different porcentage of grains (Grão) and the respective coefficients of determination $\left(r^{2}\right)$

\begin{tabular}{|c|c|c|c|c|c|c|c|}
\hline \multirow[t]{2}{*}{ Item } & \multicolumn{5}{|c|}{$\begin{array}{l}\text { Grãos (\%) } \\
\text { Grains (\%) }\end{array}$} & \multirow[t]{2}{*}{$\begin{array}{l}\text { Equação de regressão } \\
\text { Regression equation }\end{array}$} & \multirow[t]{2}{*}{$\mathrm{r}^{2}$} \\
\hline & 0 & 15 & 30 & 45 & 60 & & \\
\hline $\mathrm{NNP}^{1}$ & 34,05 & 39,14 & 50,67 & 50,91 & 54,62 & $\hat{Y}=34,43+0,3578 *$ Grão & 0,7340 \\
\hline $\mathrm{B}_{1}+\mathrm{B}_{2}^{1}$ & 51,50 & 50,66 & 39,43 & 42,65 & 41,46 & - & - \\
\hline $\mathrm{NIDN}^{1}$ & 14,46 & 10,20 & 9,90 & 6,44 & 3,92 & $\hat{Y}=13,95-0,1656 *$ Grão & 0,8427 \\
\hline $\mathrm{B}_{3}^{1}$ & 6,63 & 7,00 & 6,97 & 3,67 & 2,61 & $\hat{Y}=7,65-0 ., 076 *$ Grão & 0,5621 \\
\hline $\mathrm{C}^{1}(\mathrm{NIDA})$ & 7,83 & 3,20 & 2,93 & 2,76 & 1,32 & $\hat{Y}=6,30-0,0898 *$ Grão & 0,6497 \\
\hline
\end{tabular}

\footnotetext{
$1 \% \mathrm{~N}$ total (\% of total $\mathrm{N}$ ).
}

próxima dos valores de 41,3 e $72 \%$, respectivamente, relatados por Van Soest (1994).

O teor de umidade do material ensilado afeta o processo fermentativo no silo, atuando como barreira física à queda do $\mathrm{pH}$, favorecendo a ocorrência de fermentações indesejáveis (butírica, acética, exces- siva produção de $\mathrm{NH}_{3}$ ), as quais, por sua vez, conduzem à menor qualidade da silagem. Dessa forma, pode-se inferir que o aumento do teor de espigas teria efeito positivo sobre as características fermentativas, evidenciado pelo $\mathrm{pH}$ das silagens, o qual variou de 3,80 a 3,29 para as silagens com 0 e $60 \%$ de grãos,

R. Bras. Zootec., v.31, n.6, p.2332-2339, 2002 
respectivamente, bem como o aumento no teor de nutrientes. Considerando que Sniffen et al. (1992) sugerem que para silagens a fração A da proteína é composta exclusivamente por $\mathrm{NH}_{3}$, observa-se na Tabela 2 e Figura 1 que o aumento do teor de grãos na silagem causou aumento linear do NNP, sendo, por este aspecto, desvantajosa a inclusão de grãos. Entretanto, Van Soest (1994) relatou que silagens com elevado teor de MS e pH inferior a 4,0, as quais são consideradas como sendo de boa qualidade, apresentam seu NNP constituído, principalmente, por aminoácidos e peptídeos.

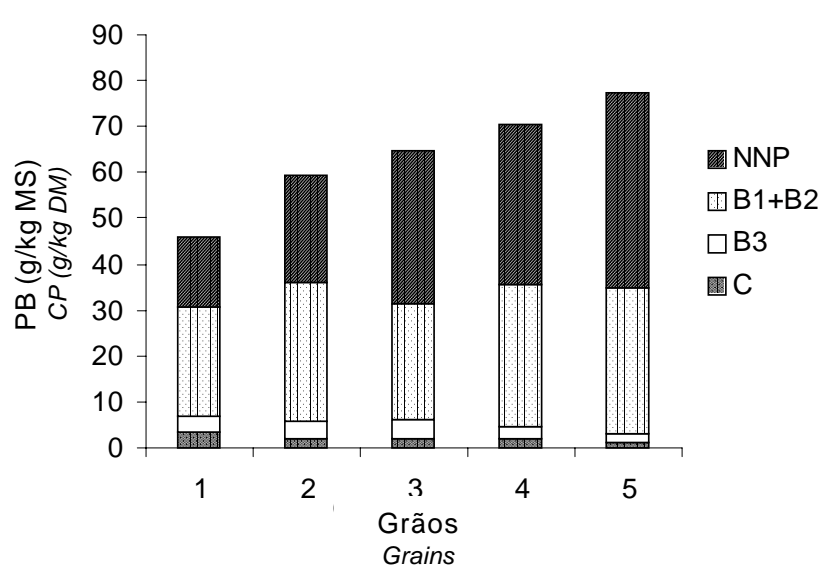

Figura 1 - Teores médios das frações nitrogenadas da silagem de milho com zero (1), 15 (2), 30 (3), 45 (4) e $60 \%$ (5) de grãos.

Figure 1 - Average content of the nitrogen fractions of corn silage with zero (1), 15 (2), 30 (3), 45 (4) and 60\% (5) of grains.
Em geral, as dietas dos ruminantes são balanceadas para atender, principalmente, os requisitos energéticos e protéicos dos rebanhos e, dessa forma, os fatores que mais afetam o custo de alimentação, quando esta se baseia em silagem de milho, são seus conteúdos em energia, FDN e PB (Allen et al., 1997). Silagens com maior conteúdo em $\mathrm{PB}$ e energia permitirão menor suplementação e, com isso, redução do custo de alimentação. Considerando a inversa relação entre consumo e FDN e digestibilidade e FDA (Mertens, 1987), pode-se inferir que a redução do teor de FDN e FDA, com o acréscimo de grãos à silagem, permi-

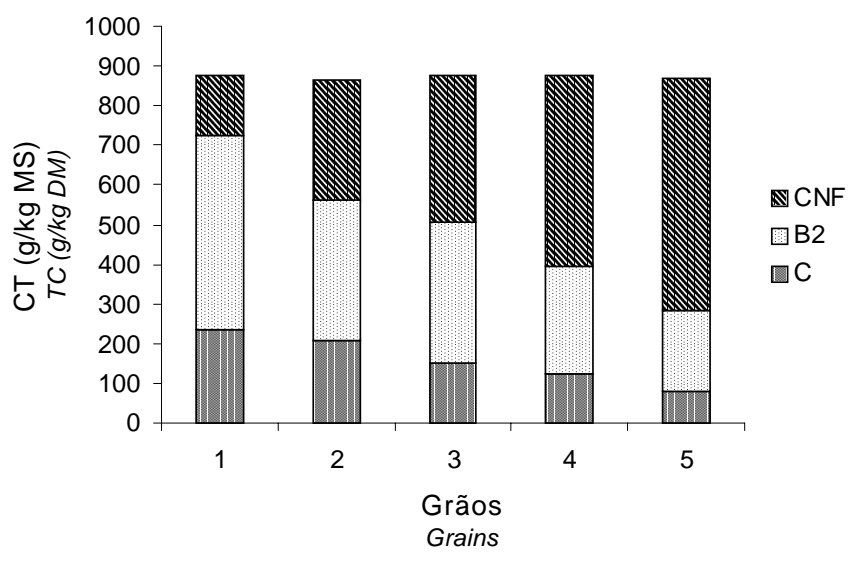

Figura 2 - Teores médios de CNF e das frações $B_{2}$ e $C$ dos carboidratos totais para a silagem de milho com zero (1), 15 (2), 30 (3), 45 (4) e 60\% (5) de grãos.

Figure 2 - Average NFC contents and $B_{2}$ and $C$ fractions in the total carbohydrates of corn silage with $0(1), 15$ (2), 30 (3), 45 (4) and 60\% (5) of grains.

Tabela 3 - Valores médios e equações de regressão para os carboidratos não-fibrosos (CNF) e frações $B_{2}$ e $C$ da silagem de milho, em função da porcentagem de grãos (Grãos) e os respectivos coeficientes de determinação ( $\left.r^{2}\right)$

Table 3 - Average values and regression equation for non-fiber carbohydrates (NFC) and $B_{2^{2}}$ and $C$ fractions of corn silage in function of grain porcentage (Grão) and the respective coefficients of determination $\left(r^{2}\right)$

\begin{tabular}{|c|c|c|c|c|c|c|c|}
\hline \multirow[t]{2}{*}{ Item } & \multicolumn{5}{|c|}{$\begin{array}{l}\text { Grãos (\%) } \\
\text { Grains (\%) }\end{array}$} & \multirow[t]{2}{*}{$\begin{array}{c}\text { Equação de regressão } \\
\text { Regression equation }\end{array}$} & \multirow[t]{2}{*}{$\mathrm{r}^{2}$} \\
\hline & 0 & 15 & 30 & 45 & 60 & & \\
\hline $\mathrm{CNF}^{1}$ & 17,51 & 34,97 & 42,35 & 54,91 & 67,34 & $\hat{Y}=19,41+0,7973 *$ grão & 0,9878 \\
\hline $\mathrm{B}_{2}^{1}$ & 55,86 & 40,94 & 40,49 & 31,23 & 23,40 & & \\
\hline $\mathrm{C}_{1}^{2}$ & 26,63 & 24,09 & 17,16 & 13,86 & 9,26 & - & - \\
\hline $\mathrm{CNF}^{2}$ & 153,55 & 302,69 & 370,35 & 481,36 & 585,10 & $\hat{Y}=144,25+7,32 *$ Grão & 0,9831 \\
\hline $\mathrm{B}_{2}^{2}$ & 489,75 & 354,40 & 354,21 & 273,82 & 203,29 & $\hat{Y}=486,57-4,734 *$ Grão & 0,9744 \\
\hline $\mathrm{C}_{2}^{2}$ & 233,50 & 208,60 & 150,14 & 121,53 & 80,51 & $\hat{Y}=243,95-2,659 *$ Grão & 0,9000 \\
\hline
\end{tabular}

$1 \%$ dos CT (\% TC).

$2 \mathrm{~g} / \mathrm{kg}$ de $M S(g / k g D M)$.

R. Bras. Zootec., v.31, n.6, p.2332-2339, 2002 
tiria maior ingestão de alimentos e maior disponibilidade de energia para os animais. A porcentagem de FDN da silagem de milho com 30 e $45 \%$ de grãos, respectivamente, está próxima à sugerida por Sniffen et al. (1992).

$\mathrm{O}$ valor nutricional da silagem é função do seu teor de grãos. A quantificação deste último em condições de fazenda não é prática e, desta forma, talvez, uma característica possa ser utilizada para estimar o teor destes, devido ao impacto que tem sobre a qualidade do alimento e o desempenho animal. Considerando a inversa relação observada entre o teor de grãos e a porcentagem de FDN e entre esta última e os índices de qualidade (produção de gás, DIVMS e NDT), a FDN poderia ser utilizada na estimação do teor de grãos em silagens de milho, pois ainda tem a vantagem de ser uma variável bastante representativa na MS do alimento, sendo a relação entre o teor de grãos e o teor de FDN obtida neste estudo, representada pela seguinte equação: $\mathrm{Y}=$ $100,37-1,3923 *$ FDN $\left(r^{2}=0,9728\right)$.

As frações nitrogenadas são apresentadas na Tabela 2 e Figura 1, nas quais pode ser observado que o acréscimo de grãos à silagem reduziu linearmente o $\mathrm{N}$ insolúvel em detergente neutro (NIDN) e as frações $\mathrm{C}$ e $\mathrm{B}_{3}$ e aumentou o NNP. A redução da fração $C$ e $B_{3}$ deve ter ocorrido em função do aumento da fração A. A porcentagem de NNP da silagem de milho com $45 \%$ de grãos está próxima à sugerida por Sniffen et al. (1992). O aumento do NNP, com o acréscimo de grãos, poderia conduzir a perdas de $\mathrm{N}$ no rúmen, se não fosse acompanhada do aumento do teor de CNF, o que provavelmente permitiria maior eficiência de utilização do mesmo.

As frações de carboidratos são apresentadas na Tabela 3 e Figura 2. O acréscimo na porcentagem de grãos aumentou linearmente o teor de $\mathrm{CNF}$ e reduziu os teores de $\mathrm{CF}$ (fração $\mathrm{B}_{2}$ ) e da fração $\mathrm{C}$. Em razão de os CNF apresentarem disponibilidade nutricional quase completa (98\%), o seu incremento na silagem aumentaria a disponibilidade de energia tanto no rúmen como nos intestinos. Entretanto, a disponibilidade ruminal aumentada dos $\mathrm{CNF}$, possivelmente, elevaria a necessidade de suplementação com proteína degradada no rúmen, uma vez que os microrganismos que utilizam estes carboidratos necessitam de aminoácidos e peptídeos para máxima eficiência (Russell et al., 1992). Caso contrário, em condições excessivas de disponibilidade de fontes energéticas (glicose) e limitação de nutrientes $(\mathrm{N})$, poderá haver utilização da energia por parte dos microrganismos, sem a concomitante produção de células, num processo conhecido como "Energy Spilling", ou dissipação de energia, por meio de ciclos fúteis de íons através da membrana na tentativa de consumir o excesso de energia (Van Kessel \& Russell, 1996; Russell, 1998).

$A$ redução dos $C F$ (fração $B_{2}+C$ ), com o acréscimo de grãos, teria efeito positivo sobre o consumo, o qual é o fator determinante da produção em animais de elevada demanda em nutrientes, e a redução da fração $C$ aumentaria a disponibilidade de energia.

$\mathrm{Na}$ Tabela 4 são apresentadas as taxas de diges-

Tabela 4 - Valores médios e equações de regressão para as taxas de digestão $\left(\mathrm{h}^{-1}\right)$ da fração $\mathrm{B}_{2}$ e carboidratos nãofibrosos (CNF), volume final de gás (VT) em $\mathrm{mL}$, digestibilidade in vitro da matéria seca (DIVMS) e NDT estimado (\%) para a silagem de milho em função da porcentagem de grãos (Grão) e os respectivos coeficientes de determinação $\left(\mathrm{r}^{2}\right)$

Table 4 - Average values and regression equation for digestion rate $\left(h^{-1}\right)$ of $B_{2}$ fraction and and non-fiber carbohydrate (NFC), gas production (GP), in vitro dry matter digestibility (IVDMD) and estimated TDN (\%) for corn silage, in function of grains proportions (Grão) and the respective coefficients of determination $\left(r^{2}\right)$

\begin{tabular}{|c|c|c|c|c|c|c|c|}
\hline \multirow[t]{2}{*}{ Item } & \multicolumn{5}{|c|}{$\begin{array}{l}\text { Grãos (\%) } \\
\text { Grains (\%) }\end{array}$} & \multirow[t]{2}{*}{$\begin{array}{l}\text { Equação de regressão } \\
\text { Regression equation }\end{array}$} & \multirow[t]{2}{*}{$\mathrm{r}^{2}$} \\
\hline & 0 & 15 & 30 & 45 & 60 & & \\
\hline $\begin{array}{l}\mathrm{CNF} \\
N F C\end{array}$ & 0,0803 & 0,2075 & 0,2662 & 0,2556 & 0,2315 & $\hat{Y}=0,0859+0,0093 *$ Grão $-0,000116 *$ Grão $^{2}$ & 0,9279 \\
\hline $\begin{array}{l}\mathrm{CF} \\
F C\end{array}$ & 0,0254 & 0,0305 & 0,0304 & 0,0291 & 0,0315 & $\hat{Y}=0,0264+0,00018$ Grão $-0,000006176 *$ Grão ${ }^{2}$ & 0,4335 \\
\hline $\begin{array}{l}\mathrm{VT} \\
G P\end{array}$ & 20,03 & 23,35 & 25,77 & 26,95 & 28,47 & $\hat{Y}=20,95+0,1333 *$ Grão & 0,9138 \\
\hline $\begin{array}{l}\text { DIVMS } \\
\text { IVDMD }\end{array}$ & 62,19 & 70,83 & 77,34 & 80,58 & 83,21 & $\hat{Y}=64,89+0,3353 *$ Grão & 0,8664 \\
\hline $\begin{array}{l}\text { NDT } \\
T D N\end{array}$ & 56,08 & 63,54 & 69,25 & 75,42 & 81,40 & $\hat{Y}=56,63+0,4168 *$ Grão & 0,9798 \\
\hline
\end{tabular}

R. Bras. Zootec., v.31, n.6, p.2332-2339, 2002 
tão dos CNF e da fração $\mathrm{B}_{2}$, o volume final de gás, a DIVMS e o NDT estimado. A adição de grãos à silagem afetou quadraticamente a taxa de digestão dos CF e CNF e, linearmente, o volume final de gás e a DIVMS e o NDT estimado. Foram estimados valores máximos para as taxas de digestão dos $\mathrm{CNF}$ e CF de 0,2723 e $0,02771 \mathrm{~h}^{-1}$, para as silagens com 40,08 e $14,57 \%$ de grãos, respectivamente.

As taxas de digestão estimadas para os CNF estão nos limites de 10 a $40 \% / h$ sugeridos por Sniffen et al. (1992) para a fração $B_{1}$ dos carboidratos. A reduzida taxa de digestão estimada para os CNF da silagem sem a presença de grãos pode ser atribuída à natureza desta fração, que, neste caso, é representada, principalmente, por ácidos orgânicos. O acréscimo de grãos, por acarretar aumento dos CNF e redução dos $\mathrm{CF}$, pode afetar os parâmetros cinéticos estimados pelos sistemas in vitro (cultura em batelada ou sistema fechado), principalmente, o acúmulo de metabólitos (ácidos orgânicos) em taxas elevadas ao ambiente de incubação, ou até mesmo a exaustão de outros nutrientes $(\mathrm{N})$, pode inibir a ação fermentativa, embora ainda existam nutrientes potencialmente digestíveis. Para o caso específico da técnica de produção de gás, a proporção molar dos ácidos graxos voláteis produzidos pode também afetar a taxa na qual os gases são produzidos, em resposta à adição de carboidratos disponíveis. É sabido que a fermentação acética gera 2 moles de $\mathrm{CO}_{2}$ por mol de acetato (produção direta) e 0,87 moles de $\mathrm{CO}_{2}$ por mol de $\mathrm{AGV}$ (produção indireta), já a produção de propionato só libera 0,87 moles de $\mathrm{CO}_{2}$ indiretamente (Beuvink \& Spoesltra, 1992). Dessa forma, o comportamento

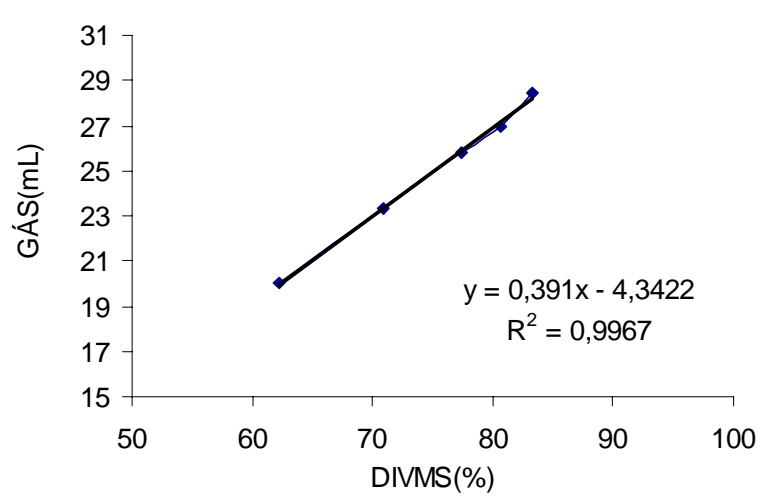

Figura 3 - Comportamento descritivo e equação de regressão para o volume de gás $(Y)$ em função da $\operatorname{DIVMS}(\mathrm{X})$.

Figure 3 - Descriptive behavior and regression equation for the gas production $(Y)$ in function of the IVDMD $(X)$.

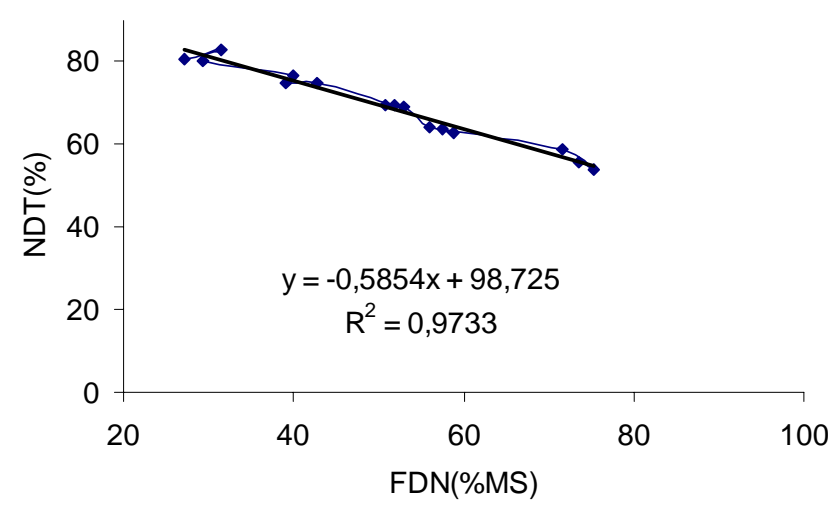

Figura 4 - Relação entre a porcentagem de FDN e o NDT estimado pelas equações do NRC (2001).

Figure 4 - Relation between the NDF percentage and the TDN estimated by NRC (2001) equations.

quadrático para as taxas de digestão estimadas para os CNF e CF pode ser explicada.

A menor taxa de digestão estimada para a fração $\mathrm{B}_{2}$ da silagem de milho com nível zero de grãos pode ser atribuída à elevada concentração de lignina em sua FDN e à ausência de carboidratos de rápida fermentação, os quais, em concentrações moderadas, tendem a estimular a degradação da fibra, pois, embora, a concentração de lignina na FDN da silagem de milho com $15 \%$ de grãos tenha sido semelhante, a taxa de digestão dos CF desta última foi bem superior.

O NDT estimado foi altamente correlacionado $(\mathrm{r}=0,95)$ com o volume final de gás e a DIVMS, sendo, portanto, ambas as técnicas sensíveis à mudança na disponibilidade de nutrientes. Entretanto, a técnica de produção de gás permitiu, adicionalmente, estimar a taxa de degradação dos CF e CNF.

A Figura 3 ilustra a relação entre a DIVMS e o volume final de gás em função do teor de grãos na silagem de milho. Ambas as técnicas foram sensíveis às alterações na disponibilidade de nutrientes nos alimentos, principalmente carboidratos, sendo, portanto, passíveis de serem utilizadas em estudos comparativos. A técnica de produção de gases mostra-se como importante ferramenta em estudos de parâmetros cinéticos das frações que compõem os alimentos (CT), uma vez que reflete a taxa e extensão na qual os componentes dos alimentos são disponibilizados aos microrganismos do rúmen. Entretanto, a aplicação das técnicas à determinação da digestibilidade de alimentos, levando-se em conta a

R. Bras. Zootec., v.31, n.6, p.2332-2339, 2002 
sua exatidão, carece de informações, particularmente, no Brasil, sendo, então, necessários estudos que contrastem o real valor nutricional dos alimentos e suas estimativas obtidas pelos sistemas in vitro.

Considerando que os CF apresentam lenta taxa de digestão e disponibilidade nutricional variável e incompleta, sendo a maior fonte de variação à digestibilidade das forrageiras (Van Soest, 1994), pode-se afirmar que o valor nutricional das silagens de milho apresenta inversa relação ao teor destes compostos. Dessa forma, o aumento do teor dos CNF, através dos grãos, aumenta a quantidade de nutrientes digestíveis (Figura 4). Portanto, o NDT destes alimentos poderia ser estimado a partir da concentração de FDN, uma vez que esta é relacionada inversamente com o teor de CNF, sendo o NDT altamente correlacionado com a porcentagem de FDN $(\mathrm{R}=$ $0,95)$. O mesmo pode ser dito para a relação entre o volume final de gás e o NDT.

\section{Conclusões}

$\mathrm{A}$ adição de grãos à silagem de milho aumentou o teor de CNF e reduziu o da FDN potencialmente digestível (fração $\mathrm{B}_{2}$ ).

O teor de grãos de uma silagem de milho pode ser estimado por intermédio do seu teor de FDN pela equação $\hat{Y}=100,37-1,3923 *$ FDN.

A técnica de produção de gás mostrou-se capaz de detectar as diferenças existentes nas amostras de silagem quanto à disponibilidade de nutrientes, o que permite inferir que a mesma possa ser utilizada também na estimação do NDT.

\section{Literatura Citada}

ALLEN, M.S.; OBA, M.; CHOI, B.R. Nutritionist's perspecive on corn hybrids for silage. In: SILAGE: FIELD TO FEEDBUNK, 1997, New York. Proceedings... New York: 1997.

ASSOCIATION OF OFFICIAL ANALYTICAL CHEMISTS AOAC. Official methods of analysis. 15.ed. Arlington, 1990. $1117 \mathrm{p}$.

BROCK, T.D.; MADIGAN, M.T.; MARTINKO, J.M. et al. Biology of microorganisms. 7.ed. Englewood Cliffs: Prentice-Hall, 1994. 909p.

BEUVINK, J.M.W.; SPOELSTRA, S.F. Interactions between substrate, fermentation end-products, buffering systems and gas production upon fermentation of different carbohydrates by mixed rumen microorganisms in vitro. Applied Microbiology and Technology, v.37, n.4, p.505-509, 1992.
LICITRA, G.; HERNANDEZ, T.M.; Van SOEST, P.J. Standardization of procedures for nitrogen fractionation of ruminant feeds. Animal Feed Science and Technology, v.57, n.4, p.347-358, 1996.

McDOUGAL, E.I. Studies on ruminal saliva. 1. The composition and output of sheep's saliva. Biochemical Journal, v.43, n.1, p.99-109, 1949.

MERTENS, D.R. Predicting intake and digestibility using mathematical models of ruminal function. Journal of Animal Science, v.64, n.5, p.1548-1558, 1987.

MERTENS, D.R. Using fiber and carbohydrate analyses to formulate dairy rations. In: INFORMATIONAL CONFERENCE WITH DAIRY AND FORAGES INDUSTRIES, 1996, Wisconsin. Proceedings... Wisconsin: 1996.

NATIONAL RESEARCH COUNCIL - NRC. Nutrients requirements of dairy cattle. 7.ed. Washington, D.C.: National Academy Press, 2001. 381p.

PELL, A.N.; SCHOFIELD, P. Computerized monitoring of gas production to measure forage digestion in vitro. Journal of Dairy Science, v.76, n.9, p.1063-1073, 1993.

RUSSELL, B.J.; O'CONNOR, J.D.; FOX, D.J. et al. A net carbohydrate and protein system for evaluation cattle diets: ruminal fermentation. Journal of Animal Science, v.70, n.12, p.3551-3581, 1992.

RUSSELL, J.B. Strategies that ruminal bacteria use to handle excess carbohydrate. Journal of Animal Science, v.76, n.8, p.1955-1963, 1998.

SISTEMA DE ANÁLISES ESTATÍSTICAS E GENÉTICAS SAEG. Guia do usuário. Viçosa, MG: Universidade Federal de Viçosa, 1993.

SCHOFIELD, P.; PITT, R.E.; PELL, A.N. Kinetics of fiber digestion from in vitro gas production. Journal of Animal Science, v.72, n.11, p.2980-2991, 1994.

SNIFFEN, C.J.; O'CONNOR, D.J.; VAN SOEST, P.J. et al. A net carbohydrate and protein system for evaluating cattle diets: carbohydrate and protein availability. Journal of Animal Science, v.70, n.12, p.3562-3577, 1992.

TILLEY, J.M.A.; TERRY, R.A. A two-stage technique for the in vitro digestion of forage crops. Journal British of Grassland Society, v.18, p.104-111, 1963.

Van KESSEL, J.S.; RUSSELL, J.B. The effect of amino nitrogen on the energetics of ruminal bacteria and its impact on energy spilling. Journal of Dairy Science, v.79, n.7, p.1237-1243, 1996.

Van SOEST, P.J. Development of a comprehensive system of feeds analysis and its applications to forages. Journal of Animal Science, v.26, p.119-128, 1967.

Van SOEST, P.J.; ROBERTSON, J.B.; LEWIS, B.A. Methods for dietary fiber, neutral detergent fiber, and nonstarch polyssacarides in relation to animal nutrition. Journal of Dairy Science, v.74, n.10, p.3583-3597, 1991.

Van SOEST, P.J. Nutritional ecology of the ruminant. 2.ed. Ithaca: Cornell University Press, 1994. 476p. 